\title{
Cryopreservation of Induced Pluripotent Stem Cells
}

\author{
Yoshitaka Miyamoto, $* \dagger+$ Hirofumi Noguchi,§ Hiroshi Yukawa, ${ }^{*}$ Koichi Oishi,* \\ Kenji Matsushita, $\dagger$ Hisashi Iwata,I[ and Shuji Hayashi*
}

\author{
*Department of Advanced Medicine in Biotechnology and Robotics, \\ Nagoya University Graduate School of Medicine, Higashi-ku, Nagoya, Japan \\ $\dagger$ Department of Oral Disease Research, National Center for Geriatrics and Gerontology, Aichi, Japan \\ $\$$ Clinical Research Center, National Center for Child Health and Development, Tokyo, Japan \\ §Department of Gastroenterological Surgery, Transplant and Surgical Oncology, \\ Okayama University Graduate School of Medicine, Dentistry and Pharmaceutical Sciences, Okayama, Japan \\ IDepartment of Biomedical Sciences, Chubu University College of Life and Health Sciences, Aichi, Japan
}

\begin{abstract}
Induced pluripotent stem (iPS) cells have attracted attention as a promising cell source for medical treatment that could replace marrow stromal cells (MSCs) and adipose tissue-derived stem cells (ASCs). These pluripotent cells can be induced in vitro and in vivo to differentiate into various tissues and organs. The cells will be useful for regenerative medicine, cell therapy, and drug screening. Vitrification is used, as well as a rapid-freeze method, for colony-forming iPS cells. However, the method requires a high degree of technical skill. We herein report a more convenient method for freezing iPS cells in suspension. We examined the proliferation potency of cryopreserved mouse iPS cells using culture medium, 10\% DMSO, 10\% glycerol, 5\% DMSO, 5\% glycerol, $5 \%$ DMSO+5\% glycerol, cell-freezing medium-DMSO, cell-freezing medium-glycerol, Cell Banker 1, Cell Banker $1^{+}$, Cell Banker 2, and Cell Banker 3 as cryopreservation solutions. Among them, Cell Banker 3 showed the highest efficacy in terms of the proliferation of mouse iPS cells. The mouse iPS cells cryopreserved in Cell Banker 3 at $-80^{\circ} \mathrm{C}$ for 12 months maintained a high proliferation rate and an undifferentiated status. The formation of teratomas was also examined. In conclusion, Cell Banker 3 allows for freezing of iPS cells in suspension.
\end{abstract}

Key words: Induced pluripotent stem (iPS) cells; Pluripotency; Cryopreservation; Slow freezing

\section{INTRODUCTION}

Induced pluripotent stem (iPS) cells $(14,17,23,24)$ are pluripotent, thus allowing them to differentiate into various cell types, and these cells have a self-renewal capability similar to that of embryonic stem (ES) cells $(20,26)$. The use of ES cells poses the ethical dilemma of requiring the breakdown of fertilized eggs and also is associated with the potential for immune rejection during cell transplantation. These problems can be solved by using iPS cells. Therefore, iPS cells will be useful for regenerative medicine, cell therapy, and drug screening.

Cryopreservation of cells is an essential technique in basic research on cell biology and in clinical use for cell transplantation. Most cell lines and primary cells are provided as frozen cells. A large number of high-quality cells can be supplied to patients at any time by using this technology. Cryopreservation of sperm, ova, and fertilized eggs is currently performed in clinical practice throughout the world. The iPS cells are an alternative promising cell source of pluripotent cells that can be used in place of marrow stromal cells (MSCs) and adipose tissue-derived stem cells (ASCs). However, the viability of human iPS cells decreases significantly during cryopreservation, as does that of human ES cells. To solve this problem, the vitrification technique used for cryopreservation of fertilized eggs, embryos, and oocytes $(5,8,18,19)$ was examined to freeze ES and iPS cells $(7,15,21)$. Vitrification is an effective cryopreservation technique, but the cells are damaged if there is an increase in osmotic pressure. Therefore, more effective and less cell toxic solutions, as well as more convenient techniques, are strongly desired.

The authors have previously reported a new cryopreservation technique in which ES cells and mouse embryonic fibroblast (MEF) feeder cells were seeded on collagen vitrigel (10). The morphology of these ES cells was good, and the survival rate was high after thawing. In contrast to vitrification, slow freezing in suspension is very convenient

Received January 31, 2011; final acceptance April 1, 2011. Online prepub date: May 8, 2012.

Address correspondence to Hirofumi Noguchi, M.D., Ph.D., Department of Gastroenterological Surgery, Transplant and Surgical Oncology, Okayama University Graduate School of Medicine, Dentistry and Pharmaceutical Sciences, 2-5-1 Shikata-cho, Okayama 700-8558, Japan.

Tel: +81-86-235-7257; Fax: +81-86-221-8775; E-mail: noguchih2006@yahoo.co.jp or noguch-h@cc.okayama-u.ac.jp 
to perform and is frequently used for the cryopreservation of various other types of cells. However, when this convenient method is used for ES and iPS cells, it is necessary to examine their condition, because such a freezing process can result in low cell viability or a loss of their pluripotency.

In the present study, the effects of cryopreservation solutions containing dimethyl sulfoxide (DMSO) or glycerol and commercially available cryopreservation solutions were compared for mouse iPS cells. We confirmed that mouse iPS cells could be preserved at $-80^{\circ} \mathrm{C}$ for at least a year and that the cells were maintained in an undifferentiated state.

\section{MATERIALS AND METHODS}

\section{Materials}

Dulbecco's modified Eagle's medium (DMEM), antibiotics (penicillin, streptomycin), and MEM nonessential amino acids solution (NEAA) were purchased from GIBCO BRL, Life Technologies (Grand Island, NY). Fetal bovine serum (FBS, BIO-WEST) was purchased from Funakoshi Co., Ltd. (Tokyo, Japan). Phosphate-buffered saline (PBS), 2-mercaptoethanol (M6250), glycerol, DMSO (D2650), and formaldehyde were obtained from SigmaAldrich (St. Louis, MO). Leukemia inhibitory factor (LIF, Chemicon) was from Dainippon Sumitomo Pharma (Osaka, Japan). Hematoxylin and eosin were purchased from Muto Pure Chemicals (Tokyo, Japan). All chemicals were reagent grade and used as received without further purification.

\section{Mice}

Nude mice (BALB/cA Jcl-nu) were purchased from Clea Japan (Osaka, Japan). These mouse studies were approved by the institutional animal care and use committees (IACUC).

\section{Cells}

The iPS cell line (iPS-MEF-Ng-20D-17) established by Professor S. Yamanaka at Kyoto University was obtained from the Cell Bank of Riken Bioresource Center (22). MEF feeder cells (Chemicon) were purchased from Dainippon Sumitomo Pharma (Osaka, Japan).

\section{iPS Cell and MEF Feeder Cell Culture}

Mouse iPS cells were cultured with mitomycin C-treated feeder cell layers as follows. First, MEF cells were cultured at $37^{\circ} \mathrm{C}$ with $5 \% \mathrm{CO}_{2}$ in MEF culture medium (DMEM supplemented with $10 \%$ heat-inactivated FBS and $1 \%$ penicillin-streptomycin) and maintained until the cells reached confluence. The cells were then treated with $50 \mu \mathrm{l}$ of $100 \times$ mitomycin $\mathrm{C}$ and incubated at $37^{\circ} \mathrm{C}$ for at least $2 \mathrm{~h}$. The cells were then cultured on $0.1 \%$ gelatin-coated plate for more than $5 \mathrm{~h}$. The iPS cells were maintained at $37^{\circ} \mathrm{C}$ with $5 \% \mathrm{CO}_{2}$ in ES cell culture medium (DMEM containing $15 \%$ FBS, $1 \times$ NEAA, $1 \mathrm{mM}$ sodium pyruvate,
$2 \mathrm{mM}$ 2-mercaptoethanol, 1\% penicillin-streptomycin and 1,000 U/ml LIF) on feeder layers of mitomycintreated MEF cells. The medium was changed to fresh ES cell culture medium everyday, and the cells were passaged every third day $(17,22,25)$.

\section{Cell Freezing and Thawing Procedures}

The basal composition of the cryopreservation medium in this study was the same as that of the ES cell culture medium. Cryoprotectant agents (glycerol and DMSO) were added to the ES cell culture medium at concentrations of 5-10\%. The other cryopreservation solutions used were the cell-freezing medium-DMSO, cell-freezing mediumglycerol, Cell Banker 1, Cell Banker 1+, Cell Banker 2, and Cell Banker 3. One milliliter of cell suspension containing $5 \times 10^{6}$ cells was quickly transferred to a $2.0-\mathrm{ml}$ freezing tube and frozen at a cooling rate of $1^{\circ} \mathrm{C} / \mathrm{min}$. After cooling to $-80^{\circ} \mathrm{C}$, the cells were stored until use (typically from 1 to 12 months). Frozen tubes were placed in a $37^{\circ} \mathrm{C}$ water bath to thaw until most ice crystals were melted. The cell suspension was then diluted 1:9 with ES cell culture medium and was centrifuged at $100 \mathrm{~g}$ for $1 \mathrm{~min}$. The supernatant was removed, and the cells were resuspended in fresh medium. Cell viability was assessed using the trypan blue exclusion test. The final concentration of trypan blue (GIBCO BRL, Grand Island, NY) was $0.2 \%$ in the experiments.

\section{Proliferation Assay of iPS Cells}

The mitomycin-treated MEF cells $\left(2 \times 10^{4}\right.$ cells $)$ were seeded on $0.1 \%$ gelatin-coated 24-well plates (BD Biosciences) with $0.5 \mathrm{ml}$ of MEF culture medium. After culture for $24 \mathrm{~h}$, the cryopreserved iPS and MEF cells $\left(3 \times 10^{4}\right.$ cells) were cultured on mitomycin $\mathrm{C}$-treated feeder cell layers. The cell proliferation was evaluated using a Cell Counting Kit-8 (CCK-8; Dojindo Laboratories, Kumamoto, Japan). The CCK-8 reagent ( $30 \mu \mathrm{l})$ was added to each well $(300 \mu \mathrm{l})$, and the reaction was allowed to proceed for up to $15 \mathrm{~min}$. The absorbance of the sample at $450 \mathrm{~nm}$ was measured against a background control using a microplate reader. The cell proliferation was evaluated after $0-72 \mathrm{~h}$.

\section{Teratoma Formation and Histological Analysis}

Mouse iPS cells were suspended at $1 \times 10^{7}$ cells $/ \mathrm{ml}$ in PBS. Nude mice were anesthetized with diethyl ether. A total of $100 \mu$ of the cell suspension $\left(1 \times 10^{6}\right.$ cells $)$ was injected subcutaneously into the dorsal flank of nude mice. Four weeks after the injection, the tumors were surgically dissected from the mice. The samples were weighed, fixed in PBS containing 4\% formaldehyde, and embedded in paraffin. The paraffin sections were stained with hematoxylin and eosin. 


\section{RESULTS}

Cryopreservation of Mouse iPS Cells and MEF Feeder Cells in Various Solutions

The iPS cells and MEF feeder cells were frozen and preserved at $-80^{\circ} \mathrm{C}$ for 3 months. These cells were cryopreserved in the following solutions: ES cell culture medium, ES cell culture medium containing 10\% DMSO,
ES cell culture medium $+10 \%$ glycerol, ES cell culture medium $+5 \%$ DMSO, ES cell culture medium $+5 \%$ glycerol, ES cell culture medium $+5 \%$ DMSO, $5 \%$ glycerol, cellfreezing medium-DMSO, cell-freezing medium-glycerol, Cell Banker 1, Cell Banker 1+, Cell Banker 2, and Cell Banker 3. In order to investigate the effects of cryopreservation on cell functions, we determined cell viability immediately after thawing (Fig. 1A) and also examined

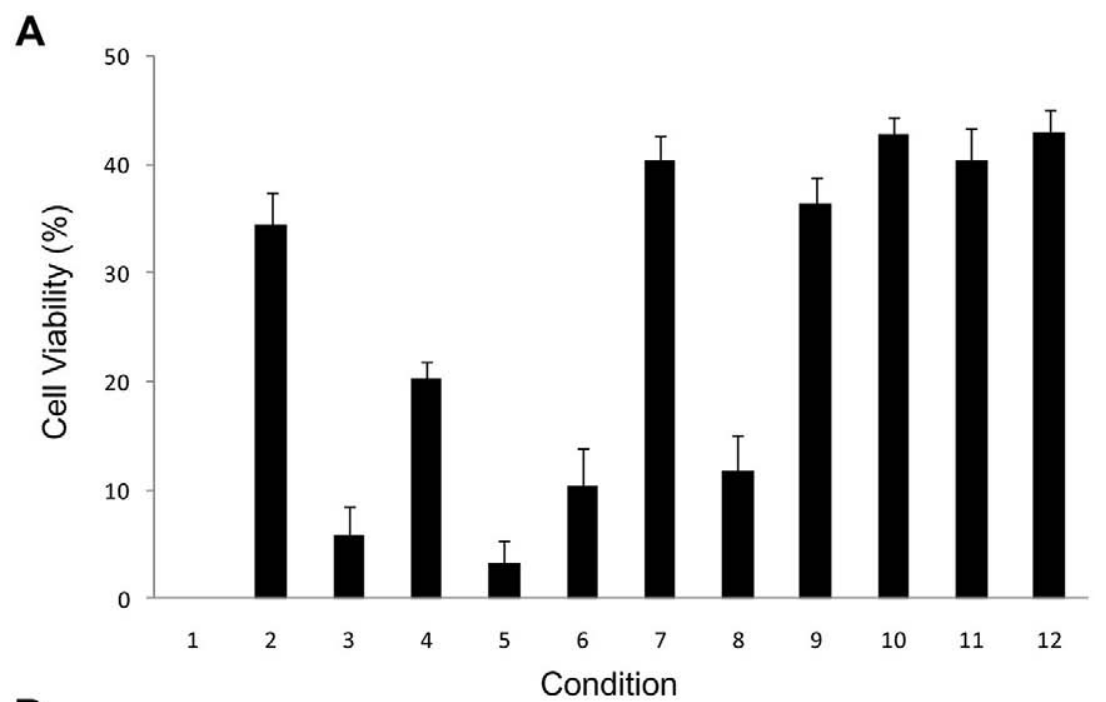

B

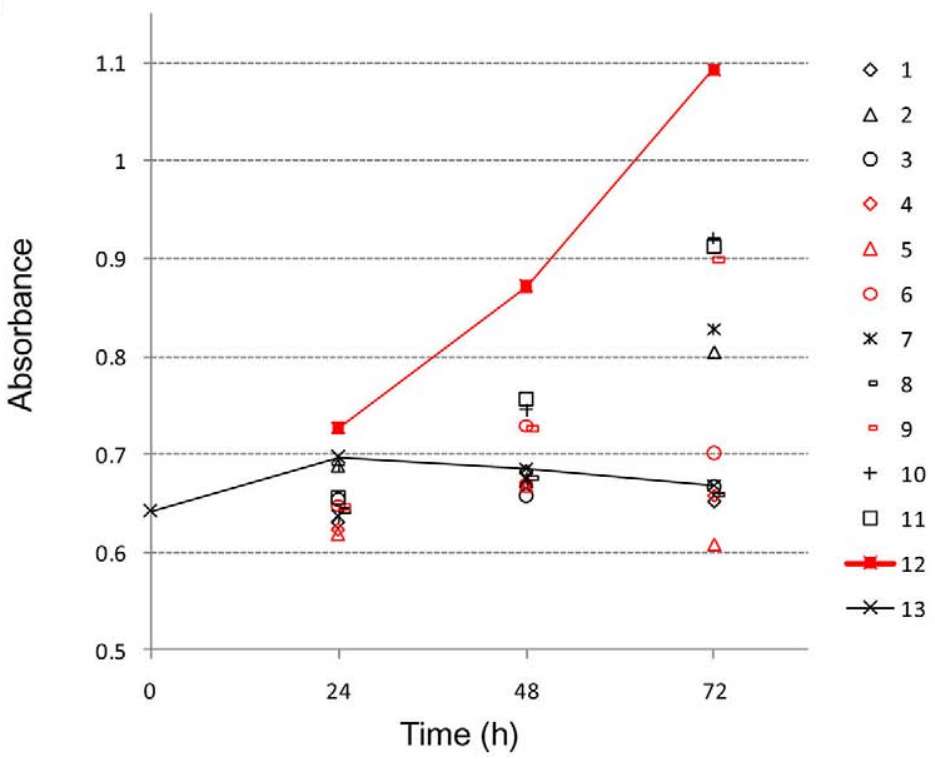

Figure 1. The viability (A) and proliferation (B) of the cryopreserved induced pluripotent stem (iPS) cells frozen using different preservation solutions. 1, Embryonic stem (ES) cell culture medium; 2, ES cell culture medium containing 10\% dimethyl sulfoxide (DMSO); 3, ES cell culture medium $+10 \%$ glycerol; 4 , ES cell culture medium $+5 \%$ DMSO; 5 , ES cell culture medium $+5 \%$ glycerol; 6 , ES cell culture medium $+5 \%$ DMSO, $5 \%$ glycerol; 7 , cell-freezing medium-DMSO; 8 , cellfreezing medium-glycerol; 9, Cell Banker 1; 10, Cell Banker $1^{+}$; 11, Cell Banker 2; 12, Cell Banker 3; 13 , only mouse embryonic fibroblast (MEF) feeder cell. The data are the means and SD of three independent experiments. 
cell proliferation (Fig. 1B). The viability of iPS cells and MEF feeder cells in 10\% DMSO, cell-freezing medium DMSO, Cell Banker 1, Cell Banker 1+, Cell Banker 2, and Cell Banker 3 was shown to be over 30\% (Fig. 1A). It was difficult to evaluate the cell viability $(10-32 \%)$ of only the MEF feeder cells (data not shown). The proliferation of the cells was monitored for $72 \mathrm{~h}$ using a commercially available cell-counting reagent (Fig. 1B). The cryopreserved iPS cells in 10\% DMSO, cell-freezing medium-DMSO, Cell Banker 1, Cell Banker $1^{+}$, Cell Banker 2, and Cell Banker 3 showed higher potency than the MEF feeder cells. The proliferation of the iPS cells frozen in Cell Banker 3 showed the highest proliferation among the 12 cryopreserved solutions. Three days after the inoculation, both iPS and MEF feeder cells adhered and grew well on MEF feeder cell layers (Fig. 2A and B). The cells cryopreserved in 10\% DMSO, cell-freezing medium-DMSO, Cell Banker 1, Cell Banker 1+, Cell Banker 2, and Cell Banker 3 were identified as iPS cells. The iPS cells frozen in Cell Banker 1, Cell Banker $1^{+}$, Cell Banker 2, and Cell Banker 3 had a morphology similar to that of undifferentiated cells (Fig. 2B; 9-12).

\section{Long-Term Cryopreservation of Mouse iPS Cells and MEF Feeder Cells}

To examine the quality of cryopreserved iPS cells in Cell Banker 3 at $-80^{\circ} \mathrm{C}$ for 12 months, we investigated the viability, proliferation, and morphology of the cryopreserved cells (Fig. 3). No significant difference in cell viability or the proliferation rate was observed from the results for iPS cells and MEF feeder cells cryopreserved for 3-12 months (Fig. 3A and B). The cells cryopreserved in Cell Banker 3 were identified as undifferentiated iPS cells (Fig. 3C, 1). Fluorescent microscopy demonstrated that green fluorescent protein genes derived from undifferentiated iPS cells were expressed in these cultures (Fig. 3C, 2).

\section{Teratoma Formation by Cryopreserved Mouse iPS Cells}

To evaluate the pluripotency of cryopreserved iPS cells, we transplanted the cells into the dorsal flank of nude mice. The iPS cells produced teratomas after transplantation (Fig. 4A). The teratomas contained various tissues, such as arteries, nerves, cartilage, adipose, and gut epithelium belonging to the three germ layers (endoderm, mesoderm, and ectoderm) (Fig. 4B-F).

\section{A}
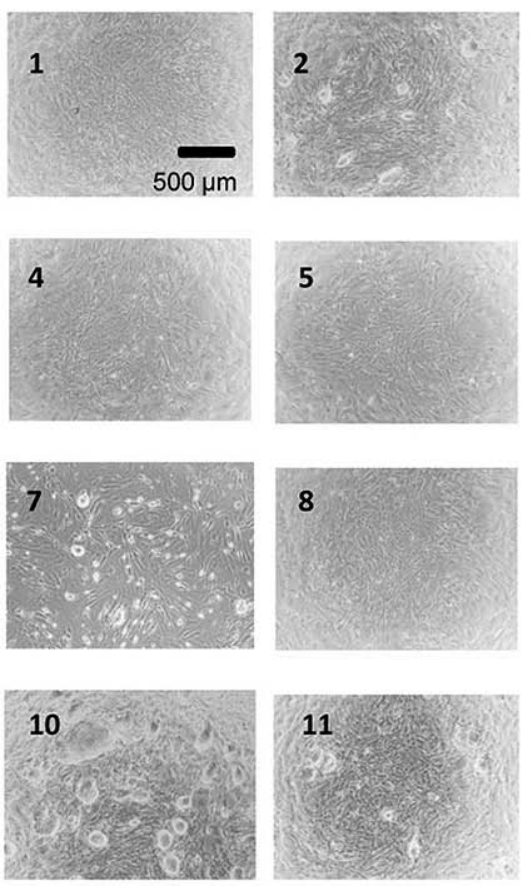
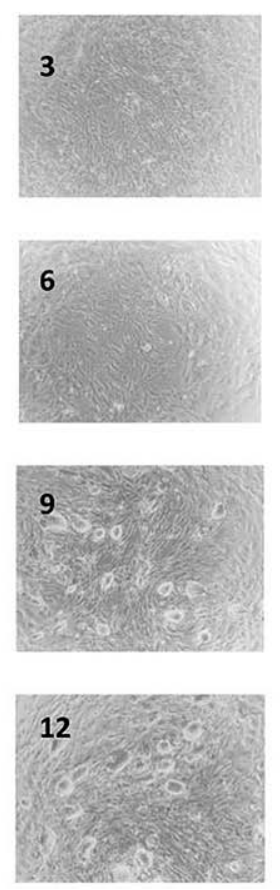

B
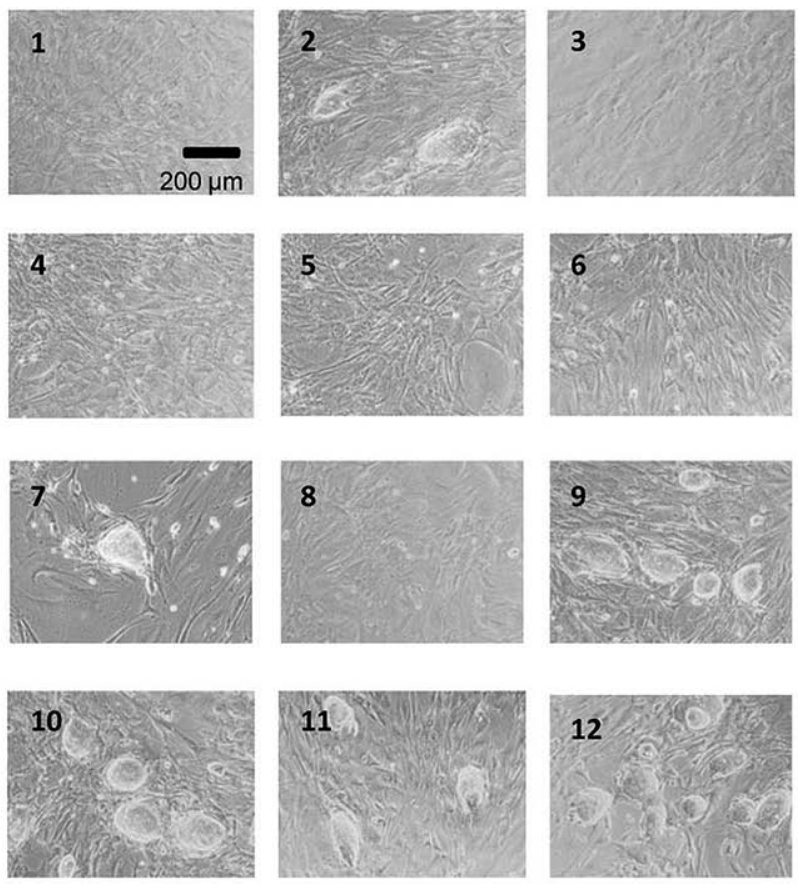

Figure 2. The phase-contrast photomicrographs of iPS cells after cryopreservation (1)-(12). 1, ES cell culture medium; 2, ES cell culture medium containing 10\% DMSO; 3, ES cell culture medium $+10 \%$ glycerol; 4 , ES cell culture medium $+5 \%$ DMSO; 5, ES cell culture medium $+5 \%$ glycerol; 6 , ES cell culture medium $+5 \%$ DMSO; $5 \%$ glycerol; 7 , cell-freezing medium-DMSO; 8 , cell-freezing medium-glycerol; 9, Cell Banker 1; 10, Cell Banker 1+; 11, Cell Banker 2; 12, Cell Banker 3. The photomicrographs were taken with $\times 40(\mathrm{~A})$ and $\times 100$ (B) objectives. The iPS cells were cultured on mitomycin-treated MEF cells for 3 days after inoculation. Scale bars: $500 \mu \mathrm{m}(\mathrm{A})$ and $200 \mu \mathrm{m}(\mathrm{B})$. 
A

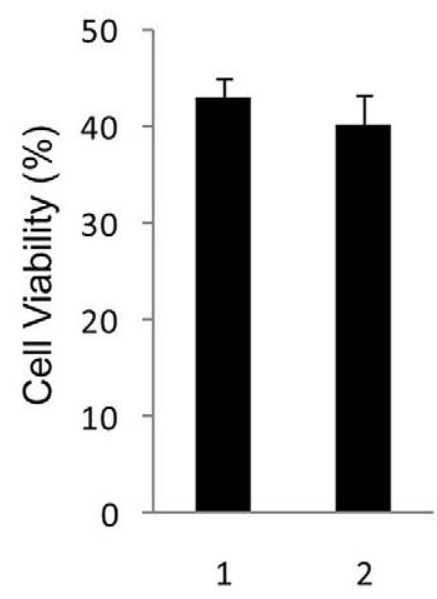

C
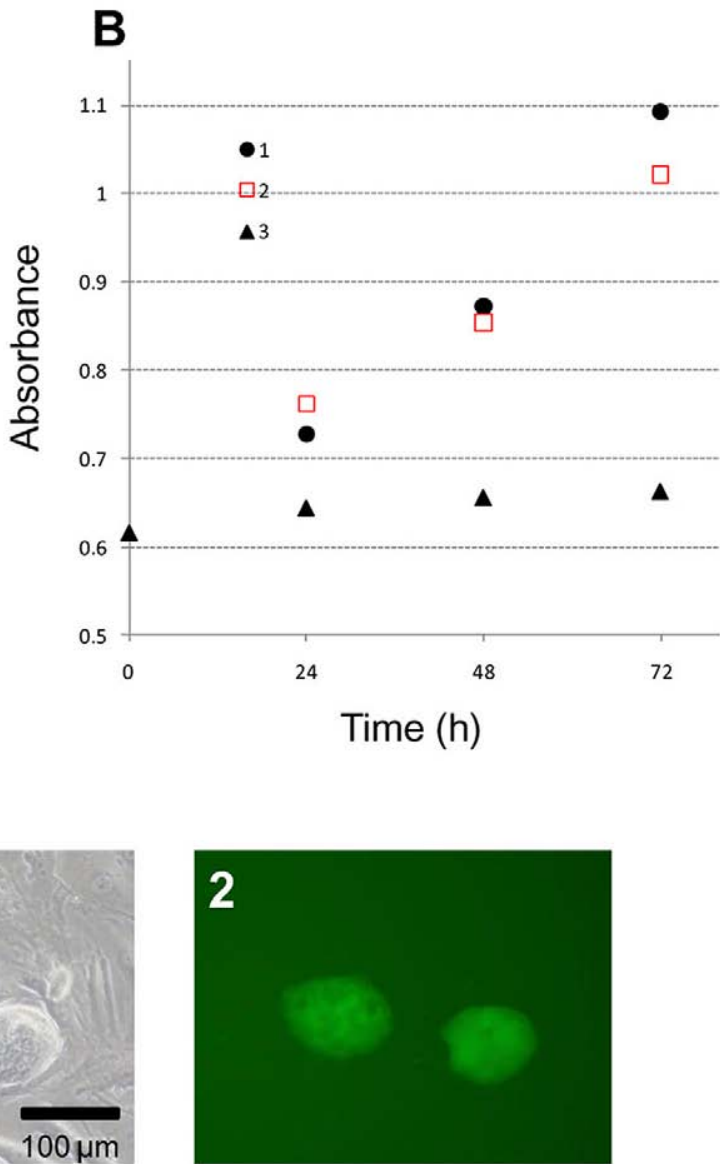

Figure 3. Evaluation of the iPS cells cryopreserved with Cell Banker 3 after 3 and 12 months of storage. (A) The viability of the cryopreserved iPS cells after 3 and 12 months of storage at $-80^{\circ} \mathrm{C}$. 1, After 3 months; 2 , after 12 months. (B) The proliferation of cryopreserved iPS cells after 3 and 12 months of storage. 1, After 3 months; 2, after 12 months; 3, only the MEF feeder cell layer. The data are the means and SD of three independent experiments. (C) The phase-contrast photomicrographs of (1) cryopreserved iPS cells after 12 months. The fluorescent photomicrograph (2) exhibited the expression of green fluorescent protein derived from undifferentiated iPS cells. (C) Scale bar: $100 \mu \mathrm{m}$.

\section{DISCUSSION}

The iPS cells are a promising cell source for regenerative medicine and cell transplantation therapy. The vitrification process has been used as a rapid-freezing method for colony-forming iPS and ES cells $(7,15,21)$. However, this method requires a high degree of technical skill. We herein report a convenient method for freezing iPS cells in suspension.

In recent years, a wide variety of cryopreservation solutions have been examined to preserve cells without compromising their viability. DMSO and glycerol are conventionally used for the cryopreservation of cells, but they may affect cell functions because of their cytotoxicity $(1,9)$. Either disaccharide trehalose (2-4), oligosaccharide (12), sericin $(11,13)$, or antifreeze proteins (AFP) (6) can be used as a cryopreservation reagent.
In the present study, the functions of cryopreserved iPS cells were investigated using the 12 kinds of newly prepared and commercially available cryopreservation solutions. The iPS cells cryopreserved at $-80^{\circ} \mathrm{C}$ using Cell Banker 3 showed the highest cell viability and proliferation of all the solutions examined in this study (Fig. 1). In addition, the iPS cells cryopreserved in Cell Banker 3 at $-80^{\circ} \mathrm{C}$ for 12 months maintained a high proliferation rate and remained undifferentiated (Fig. 3), and these cells formed teratomas when injected into nude mice (Fig. 4). The cryopreservation technique using Cell Banker 3 can be widely used because it does not require any special technical skills.

The other serum-containing cryopreservation solutions, such as the prepared solutions (DMSO), Cell Banker 1, and Cell Banker $1^{+}$, and serum-free Cell Banker 2, were 

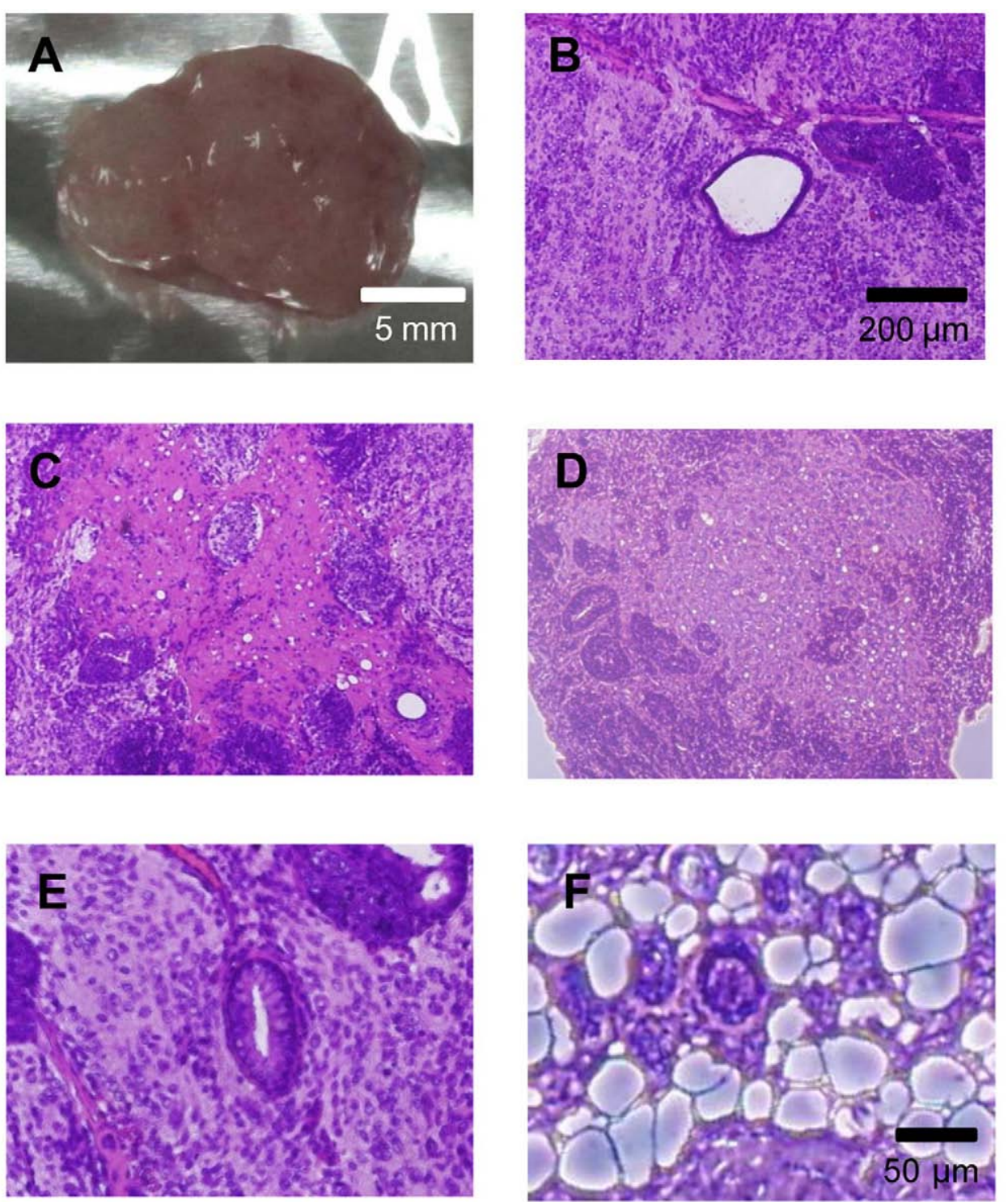

Figure 4. Teratoma formation by iPS cells. Various tissues were present in teratomas derived from iPS cells. (A) Four weeks after the injection, the teratoma was surgically dissected from the mice. (B-F) Slides were stained with hematoxylin and eosin. (B) Artery-like structures. (C) Nerve-like structures. (D) Cartilage-like structures. (E) Gut epithelium-like structures. (F) Adipose-like structures.

also effective for the preservation of iPS cells. In particular, serum-free cryopreservation solutions (Cell Banker 2 and Cell Banker 3) will be useful for regenerative medicine and transplantation.

We previously reported that Cell Banker 2 was effective for the cryopreservation of mouse and human ASCs $(11,16)$. Comparison of the viability, proliferation, and multipotency of mouse ASCs between Cell Banker 2 and Cell Banker 3 showed that Cell Banker 3 led to better preservation of the cells (data not shown). Cell Banker 3 had a similar effect on the preservation of mouse iPS cells as on mouse ASCs and is being used for the preservation of embryos and tissue stem cells, as well as primary hepatocytes, etc.

In conclusion, Cell Banker 3 allows for the effective freezing of iPS cells in suspension.

ACKNOWLEDGMENTS: We thankMs. Yumie Koshidaka (Nagoya University) for her technical assistance. The present work was supported in part by the Health and Labor Sciences Research Grants from the Ministry of Health, Labour and Welfare. The authors declare no conflicts of interest. 


\section{REFERENCES}

1. Adler, S.; Pellizzer, C.; Paparella, M.; Hartung, T.; Bremer, S. The effects of solvents on embryonic stem cell differentiation. Toxicol. In Vitro 20:265-271; 2006.

2. Crowe, J. H.; Crowe, L. M. Preservation of mammalian cellsLearning nature's tricks. Nat. Biotechnol. 18:145-146; 2000.

3. Crowe, J. H.; Crowe, L. M.; Jackson, S. A. Preservation of structural and functional activity in lyophilized sarcoplasmic reticulum. Arch. Biochem. Biophys. 220:477-484; 1983.

4. Crowe J. H.; Crowe, L. M.; Mouradian, R. Stabilization of biological membranes at low water activities. Cryobiology 20:346-356; 1983.

5. Dobrinsky, J. R. Advancements in cryopreservation of domestic animal embryos. Theriogenology 57:285-302; 2002.

6. Fletcher, G. L.; Hew, C. L.; Davies, P. L. Antifreeze proteins of teleost fishes. Annu. Rev. Physiol. 63:359-390; 2001.

7. Fujioka, T.; Yasuchika, K.; Nakamura, Y.; Nakatsuji, N.; Suemori, H. A simple and efficient cryopreservation method for primate embryonic stem cells. Int. J. Dev. Biol. 48:1149-1154; 2004.

8. Kuleshova, L.; Gianaroli, L.; Magli, C.; Ferraretti, A.; Trounson, A. Birth following vitrification of a small number of human oocytes: Case report. Hum. Reprod. 14: 3077-3079; 1999.

9. Lovelock, J. E.; Bishop, M. W. Prevention of freezing damage to living cells by dimethyl sulphoxide. Nature 183:1394-1395; 1959.

10. Miyamoto, Y.; Enosawa, S.; Takeuchi, T.; Takezawa, T. Cryopreservation in situ of cell monolayers on collagen vitrigel membrane culture substrata: Ready-to-use preparation of primary hepatocytes and ES cells. Cell Transplant. 18:619-626; 2009.

11. Miyamoto, Y.; Oishi, K.; Yukawa, H.; Noguchi, H.; Sasaki, M.; Iwata, H.; Hayashi, S. Cryopreservation of human adipose tissue-derived stem/progenitor cells using the silk protein sericin. Cell Transplant. 21:617-622; 2012.

12. Miyamoto, Y.; Suzuki, S.; Nomura, K.; Enosawa, S. Improvement of hepatocyte viability after cryopreservation by supplementation of long-chain oligosaccharide in the freezing medium in rats and humans. Cell Transplant. 15:911-919; 2006.

13. Miyamoto, Y.; Teramoto, N.; Hayashi, S.; Enosawa, S. An improvement in the attaching capability of cryopreserved human hepatocytes by a proteinaceous high molecule, Sericin, in the serum-free solution. Cell Transplant. 19:701-706; 2010.

14. Narazaki, G.; Uosaki, H.; Teranishi, M.; Okita, K.; Kim, B.; Matsuoka, S.; Yamanaka, S.; Yamashita, J. K. Directed and systematic differentiation of cardiovascular cells from mouse induced pluripotent stem cells. Circulation 118: 498-506; 2008.

15. Nishigaki, T.; Teramura, Y.; Suemori, H.; Iwata, H. Cryopreservation of primate embryonic stem cells with chemically-defined solution without $\mathrm{Me}_{2} \mathrm{SO}$. Cryobiology 60:159-164; 2010.

16. Oishi, K.; Noguchi, H.; Yukawa, H.; Miyazaki, T.; Kato, R.; Kitagawa, Y.; Ueda, M.; Hayashi, S. Cryopreservation of mouse adipose tissue-derived stem/progenitor cells. Cell Transplant. 17:35-41; 2008.

17. Okita, K.; Ichisaka, T.; Yamanaka, S. Generation of germlinecompetent induced pluripotent stem cells. Nature 448: 313-317; 2007.

18. Polge, C.; Smith, A. U.; Parkes, A. S. Revival of spermatozoa after vitrification and dehydration at low temperatures. Nature 164:666; 1949.

19. Rall, W. F.; Fahy, G. M. Ice-free cryopreservation of mouse embryos at -196 degrees $\mathrm{C}$ by vitrification. Nature 313:573-575; 1985.

20. Reubinoff, B. E.; Pera, M. F.; Fong, C. Y.; Trounson, A.; Bongso, A. Embryonic stem cell lines from human blastocysts: Somatic differentiation in vitro. Nat. Biotechnol. 18:399-404; 2000.

21. Reubinoff, B. E.; Pera, M. F.; Vajta, G.; Trounson, A. O. Effective cryopreservation of human embryonic stem cells by the open pulled straw vitrification method. Hum. Reprod. 16:2187-2194; 2001.

22. Takahashi, K.; Okita, K.; Nakagawa, M.; Yamanaka, S. Induction of pluripotent stem cells from fibroblast cultures. Nat. Protoc. 2:3081-3089; 2007.

23. Takahashi, K.; Tanabe, K.; Ohnuki, M.; Narita, M.; Ichisaka, T.; Tomoda, K.; Yamanaka, S. Induction of pluripotent stem cells from adult human fibroblasts by defined factors. Cell 131:861-872; 2007.

24. Takahashi, K.; Yamanaka, S. Induction of pluripotent stem cells from mouse embryonic and adult fibroblast cultures by defined factors. Cell 126:663-676; 2006.

25. Tateishi, K.; He, J.; Taranova, O.; Liang, G.; D’Alessio, A. C.; Zhang, Y. Generation of insulin-secreting isletlike clusters from human skin fibroblasts. J. Biol. Chem. 283:31601-31607; 2008.

26. Thomson, J. A.; Itskovitz-Eldor, J.; Shapiro, S. S.; Waknitz, M. A.; Swiergiel, J. J.; Marshall, V. S.; Jones, J. M. Embryonic stem cell lines derived from human blastocysts. Science 282:1145-1147; 1998. 